\title{
Rancang Bangun Sistem Informasi Desa Manulondo Berbasis Web
}

\author{
Maria Yuniarti Nggewa ${ }^{1}$, Ferdinandus Lidang Witi $^{2}$ \\ ${ }^{1,2}$ Sistem Informasi, Teknologi Informasi, Universitas Flores, Ende, Indonesia \\ Email: ${ }^{1}$ mariamaria07031998@ gmail.com, ${ }^{2}$ ferdylidang2017@gmail.com
}

\begin{abstract}
This research aimsto produce a village web-based information system design in Manulondo Village. This application contains the design of a village information system including village profiles, population information, and village potential information. This research uses the method waterfall. The research stages include data collection, analysis, design, coding, implementation testing. The trial using BlackBox Testing. That is by testing the user interface system to find out whether the user interface contained in this application can function properly as expected. That results of the software design in the form of a web-based Manulondo Village information system, consist of, serach for population information an village potential information.
\end{abstract}

Keywords: information, system, population, village potential, web.

\begin{abstract}
ABSTRAK
Penelitian ini bertujuan untuk menghasilkan rancang bangun sistem informasi desa berbasis web di Desa Manulondo. Aplikasi ini memuat rancang bangun sistem informasi desa meliputi profil desa, informasi kependudukan, dan informasi potensi desa. Penelitian ini menggunakan metode waterfall. Tahapan penelitian mencakup pengumpulan data, analisis, desain, coding, pengujian implementasi. Uji coba menggunakan Black Box Testing. Yaitu dengan melakukan pengujian sistem antarmuka user agar mengetahui apakah antarmuka user yang terdapat dalam aplikasi ini dapat berfungsi dengan baik sesuai dengan yang diharapkan. Hasil rancang bangun perangkat lunak berupa sistem informasi Desa Manulondo berbasis web antara lain dalam pencarian informasi kependudukan dan informasi potensi desa.
\end{abstract}

Kata Kunci: sistem informasi, kependudukan, potensi desa, web.

\section{Pendahuluan}

Pada era globalisasi saat ini, perkembangan teknologi informasi dan komunikasi sangat dibutuhkan dalam semua aspek kehidupan manusia. Dengan adanya Rumusan masalah dalam penelitian ini adalah sistem informasi global dapat menghasilkan bagaimana merancang bangun sistem informasi desa keterbukaan informasi publik. Desa Manulondo Manulondo berbasis web? memiliki jumlah penduduk sebanyak 1056 jiwa yang terdiri dari laki-laki 509 jiwa dan perempuan 547 jiwa dengan jumlah kepala keluarga sebanyak 313 KK (Desa Manulondo, 2021). Desa Manulondo belum memanfaatkan teknologi informasi berupa Sistem Informasi Desa. Sehingga pelayanan informasi kepada masyarakat yang membutuhkan informasi tentang tentang desa dinilai kurang efektif. Berdasarkan uraiana di atas, maka peneliti tertarik untuk mengambil penelitian di desa Manulondo dengan mengahsilkan
rancang bangun sistem informasi desa Manulondo berbasis web. Oleh karen iitu, untuk membuktikannya penulis merasa perlu untuk melakukan penelitian tentang "Rancang Bangun Sistem Informasi Desa Manulondo Berbasis Web".

Tujuan penelitian dalam penelitian ini adalah untuk membangun rancang bangun sistem informasi desa Manulondo berbasis web.

\section{Metode Penelitian}

Metodologi yang digunakan dalam penelitian ini menggunakan model waterfall. Menurut Basil (2012) Model Waterfall terdiri 5 tahap yang dapat dijabarkan seperi pada gambar 1. 


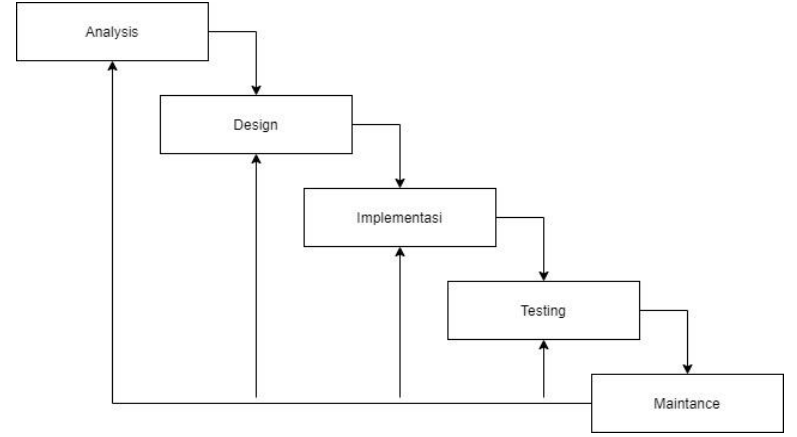

Gambar 1. Model waterfall

proses laporan. Proses master data di mana admin melakukan entri data galeri desa, orgnaisasidan UMKM, perangkat desa, dan kependudukan. Proses kedua yakni proses potensi desa dimana admin melakukan entri data, potensi desa kerajinan dan potensi desa pertanian kemudian data-data tersebut akan diproses di sistem kemudian admin juga akan mendapatkan informasi mengenai potensi desa kerajinan dan informasi pertanian. Proses ketiga yakni proses pembuatan laporan di mana admin akan melakukan pencetakan laporan yakni laporan informasi potensi desa dan laporan informasi kependudukan.

Metode waterfall memiliki tahapan-tahapan yaitu analisis dengan menaganalisa data yang digunakan agar dapat implementasikan ke dalam sistem yang akan dibangun, Design (rancang) dengan menentukan rancangan awal serta kebutuhan-kebutuhan aplikasi guna membangun aplikasi, implementasi (praktik) dengan menngunakan bahasa pemrograman PHP dan basis data MYSQL, testing (pengujian) dengan menggunakan pengujian Blackbox, maintance (perawatan) dengan melakukan pemeliharaan suatu software.

\section{Hasil dan Pembahasan}

\subsection{Desain Sistem}

Desain sistem informasi Desa Manulondi meliputi Data Flow Diagram (DFD).

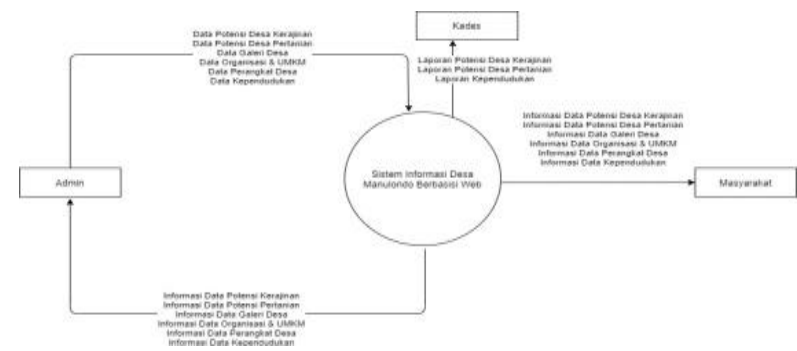

Gambar 2. DFD Level 0

Pada diagram DFD Level 0 menjelskan model proses secara keseluruhan sistem dimana admin menginput data-data ke dalam sistem kemudian sistem akan memproses data-data tersebut dan menghasilkan informasi yang dibutuhkan.

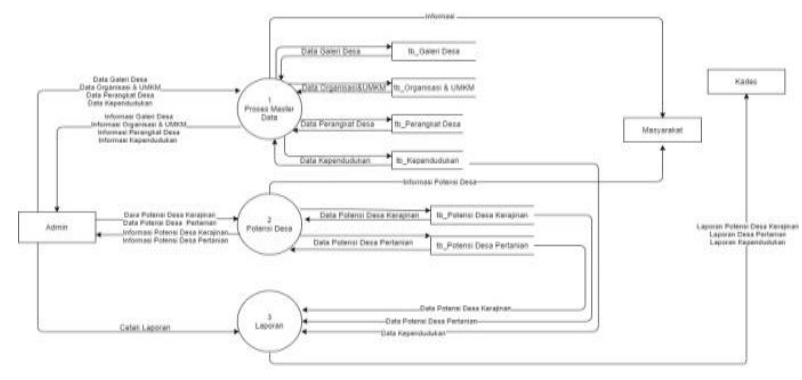

Gambar 3. DFD Level 1

Pada Data Flow Diagram Level 1 menjelaskan tiga buah proses yakni proses master data, potensi desa dan

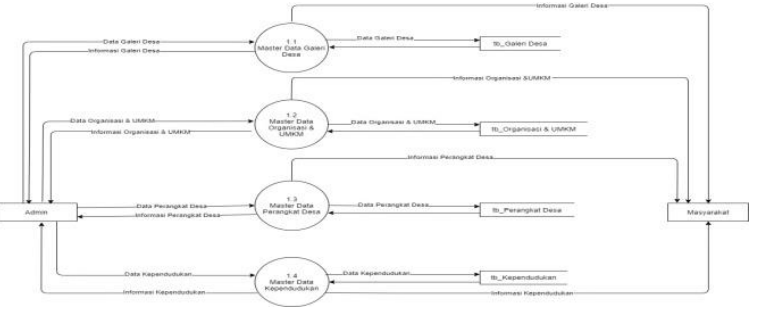

Gambar 4. DFD Level 2 Proses 1

Data Flow Diagram Level 2 Proses 1 terdapat 4 proses yakni proses master data galeri desa, master data organisasi dan UMKM, dan master data kependudukan. Admin dalam hal ini user melakukan entry data pada kedua proses tersebut dan dan mendapatkan informasi data dari masing-masing proses ini. Masing-masing proses ini juga memiliki tabel yang berbeda-beda yakni pada proses 1.1 menyimpan data pada tb_galeri desa, pada proses 1.2 menyimpan data pada tb_organisasi dan UMKM, pada proses 1.3 menyimpan data pada tb_perangkat desa, dan pada proses 1.4 menyimpan data pada tb_kependudukan. Dari keempat proses ini masyarakat akan mendapatkan informasi data dari setiap proses.

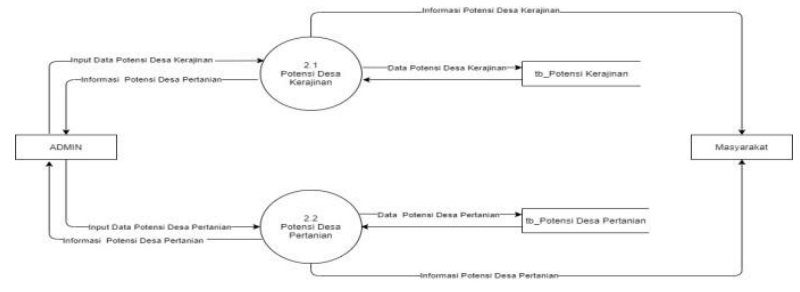

Gambar 5. DFD Level 2 Proses 2

Pada level 2 ini terdapat 2 proses yakni proses potensi desa kerajinan dan proses potensi desa pertanian. Admin dalam hal ini user melakukan entry data pada kedua proses tersebut dan mendapatkan informasi potensi desa kerajinan dan informasi potensi pertanian. Admin dalam hal ini user melakukan entry data pada kedua proses tersebut dan mendapatkan informasi potensi desa kerajinan dan informasi potensi pertanian. Masing-masing proses ini memiliki tabel yang berbedayakni pada proses 2.1 menyimpan data pada 
tb_potensi kerajinan dan proses 2.2 menyimpan data pada tb_potensi desa pertanian.

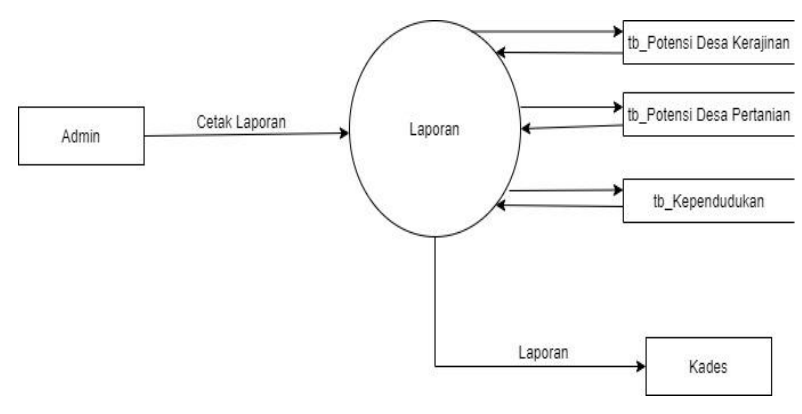

Gambar 6. DFD Level 2 Proses 3

Pada Data Flow Diagram Level 2 Proses 3 di atas merupakan uraian dari proses 3 pada level 1. Admin dalam hal ini user melakukan cetak laporan. Laporanlaporan ini yakni laporan potensi desa kerajinan, laporan desa pertanian, dan laporan kependudukan dan kepala desa akan mendaptkan laporan tersebut.

\subsection{Implementasi Sistem}

Implementasi sistem merupakan tahap penerapan dari hasil perancangan yang telah dibuat sebelumnya. Implementasi bertujuan untuk menghasilkan sebuah sistem informasi yang sesuai dengan kebutuhan.

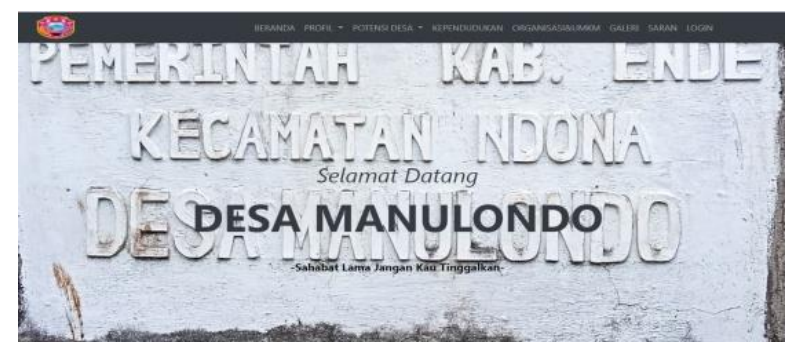

Gambar 7. Implementasi Menu Utama

Implementasi menu utama terdiri atas logo, beranda, profil desa, kependudukan, organisasi dan UMKM, galeri, saran, gambar Kantor Desa Manulondo serta form untuk login.

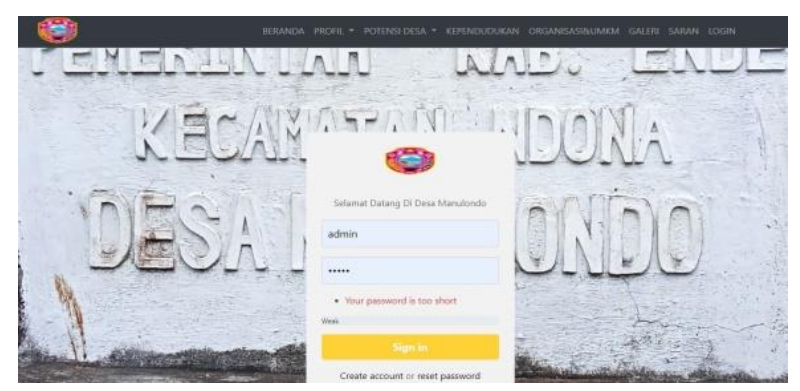

Gambar 8. Implementasi Login Admin
Implementasi login admin difungsikan oleh admin dengan mengisi username dan pasword yang valid agar dapat menjelaskan sistem.

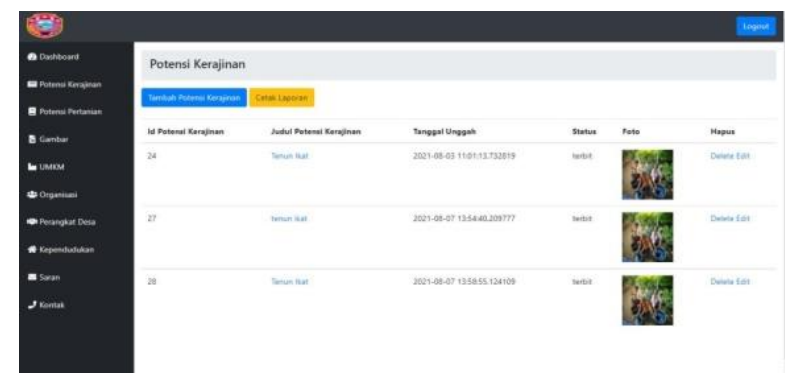

Gambar 9. Implementasi Menu Potensi Kerajinan

Implementasi potensi kerajinan menapilkan judul potensi kerajinan, tanggal unggah status dan foto. Sebagai admin dapat menambha potensi kerajinan desa Manulondo dengan mengisi pada kolom menu tambah potensi kerajinan dan mencetak laporan.

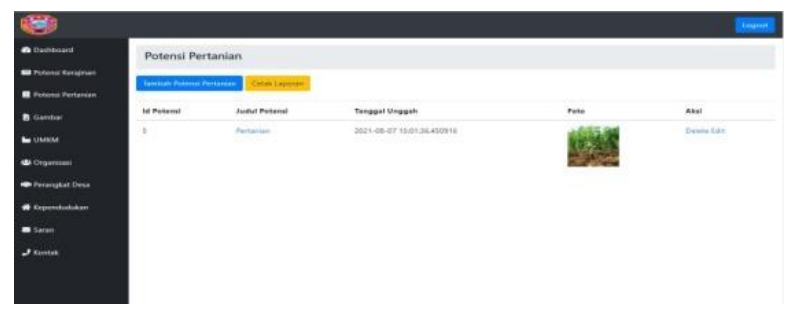

Gambar 10. Implementasi Menu Potensi Pertanian

Implementasi potensi pertanian sebagai admin dapat menambah potensi pertanian Desa Manulondo di menu kolom tambah potensi pertanian dan mencetak laporan.

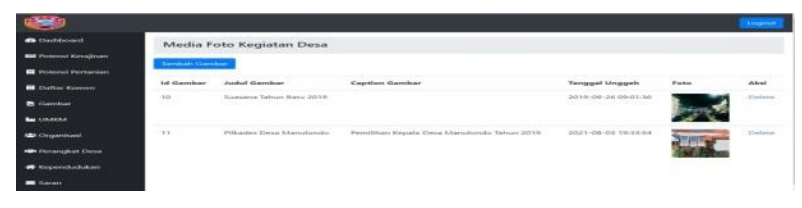

Gambar 11. Implementasi Menu Galeri

Implementasi menu galeri sebagai admin dapat menambah foto kegiatan Desa Manulondo di menu tambah gambar. Admin dapat menambahkan informasi yang terdiri dari id gambar, judul gambar, caption gambar, tanggal unggah, foto dan aksi untuk menghapus informasi gambar kegiatan desa Manulondo.

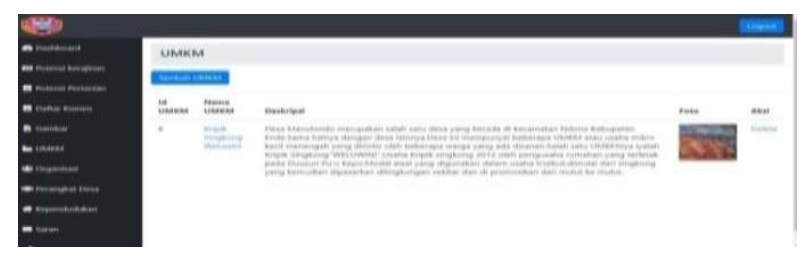

Gambar 12. Implementasi Menu UMKM 
Implementasi UMKM sebagai admin dapat menambahkan jenis UMKM yang ada di Desa Manulondo dengan mengisi kolom menu tambah UMKM.

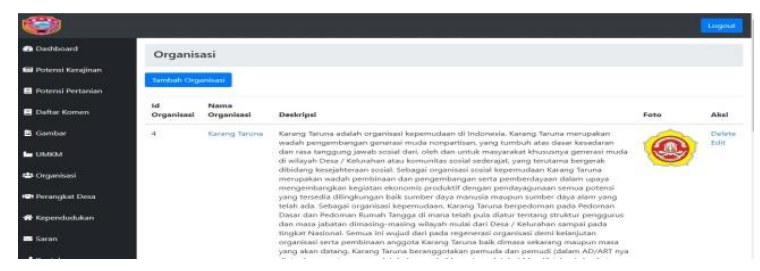

Gambar 13. Implementasi Menu Organisasi

Implementasi menu organisasi sebagai admin dapat menambah organisasi di Desa Manulondo di menu tambah organisasi dengan mengisi id organisasi, nama organisasi, deskripsi, foto dan aksi.

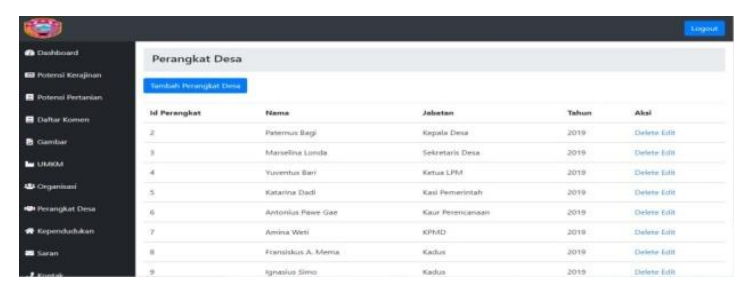

Gambar 14. Implementasi Menu Perangkat Desa

Implementasi perangkat desa menampilkan id perangkat, nama jabatan, tahun dan aksi untuk menghapus. Sebagai admin dapat menambah perangkat desa sesuai dengan keadaan di Desa Manulondo dengan mengisi kolom tambah perangkat desa.

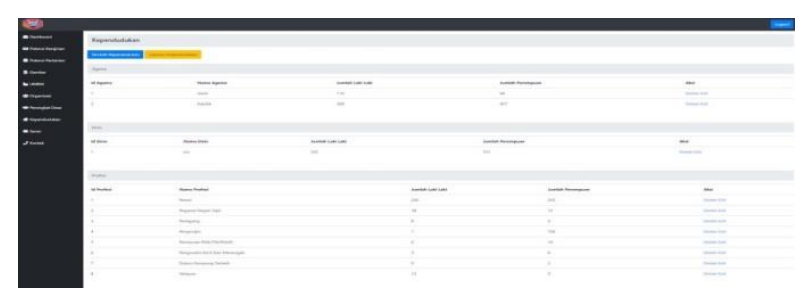

Gambar 15. Implementasi Menu Kependudukan

Implementasi menu kependudukan menampilkan id agama, nama agama, etnis profesi, jumlah laki-laki, jumlah perempuan dan aksi. Sebagai admin dapat menambah data kependudukan Desa Manulondo dengan mengupdate pada menu kependudukan dan mencetak laporan.

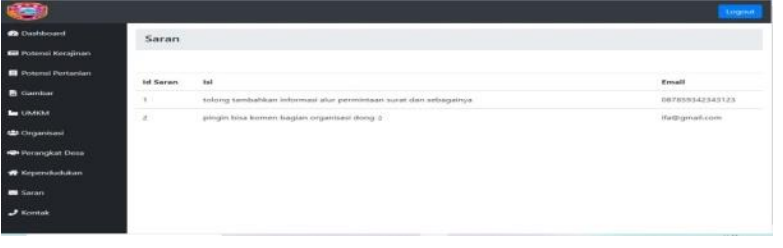

Gambar 16. Implementasi Menu Saran

Implementasi menu saran menampilkan menu id saran, isi dan email.

\section{Kesimpulan}

Berdasarkan hasil penelitian rancang bangun sistem informasi desa Manulondo dapat ditarik kesimpulan bahwa rancang bangun sistem informasi desa Manulondo dengan bahasa Pemrograman PHP dan database MYSQL serta design perangkat lunak menggunakan DFD, dan relasi tabel yang menghasilkan sebuah sistem informasi desa Manulondo dan dapat membantu memudahkan pemerintah desa dalam melayani masyarakat serta masyarakat untuk mengakses informasi tentang desa.

\section{Ucapan Terimakasih}

Peneliti mengucapkan limpah terima kasih kepada Kampus Universitas Flores dan Kantor Desa Manulondo yang telah membantu peneliti dalam melaksanakan penelitian.

\section{Referensi}

[1] Jimi, A. (2019). Rancang Bangun Sistem Informasi Desa Berbasis Website (Studi Kasus Desa Netpala). Jurnal Pendidikan Tekologi Informasi (JUKANTI), 2(1), 1-7. https://doi.org/10.37792/jukanti.v2il.17

[2] Londa, M.A., Witi,F.L., Informasi, F.T., \& Flores, U. (n.d). DI UNIVERSITAS FLORES MENGGUNAKAN STANDART ISO 9126.

[3] Suprihadi, S., Wijaya, A. F., \& Mayopu, R. G (2016). Perancangan Dan Implementasi Sistem Informasi Desa Wisata Kandri Berbasis Web. CCIT Journal, 9 (3), 276-289. https://doi.org/10.33050/ccit.v9i3.459

[4] Syukron, A. (2019).Perancangan Sistem Informasi Administrasi Kependudukan Desa Berbasis Website Pada Desa Winong. Bianglala Informatika, 7(1), 16-21. https://doi.org/10.31294/bi.v7il.5790

[5] Rozi, Zainal A. ; smmitdev community.2015.Boostrap Desain Frame Work. Jakarta:PT.Elex Media Computindo. 